Report No. ORNL/Sub/98-SY382/03

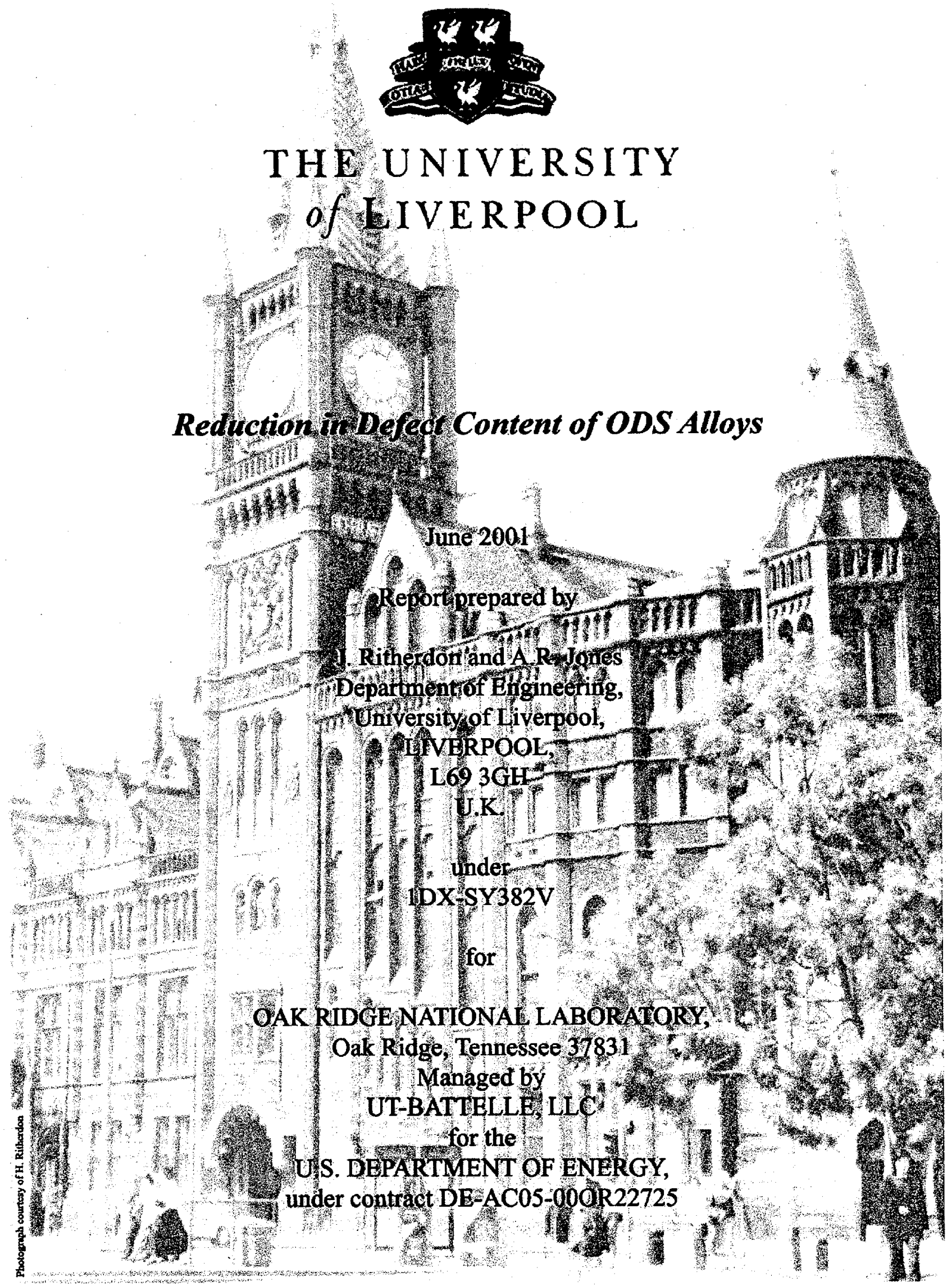




\section{Reduction in Defect Content of ODS Alloys}

June 2001

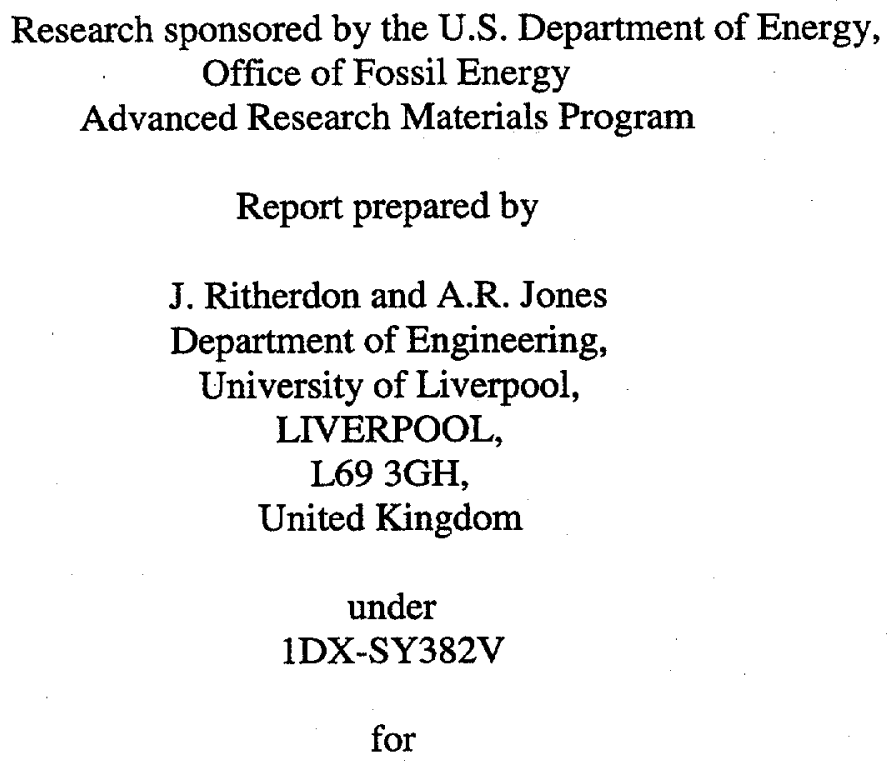

OAK RIDGE NATIONAL LABORATORY,

Oak Ridge, Tennessee 37831

Managed by

UT-BATELLE, LLC

for the

U.S. DEPARTMENT OF ENERGY

under contract DE-AC05-00OR22725 


\section{CONTENTS}

1 Introduction

2 Defects and their origins

2.1 Stringers of $\mathrm{Al}_{\mathrm{x}}(\mathrm{O}, \mathrm{N})_{\mathrm{y}}$

2.2 Regions depleted in aluminium and dispersoid

2.3 Fine-grained stringers

2.4 Acicular precipitates

3 Degassing and consolidation heat treatments

3.1 Degassing behaviour of ODS alloy powders

3.2 Pre-consolidation heat treatments and powder oxidation

3.3 Hydrogen purging to reduce powder oxidation

3.4 Cold compaction to reduce powder oxidation

4 Powder separation techniques

4.1 The fluidised bed separation technique

4.2 Separation of seed powders from iron-based powder

5 Production schedules for lower defect ODS alloys

5.1 Reduction of $\mathrm{Al}_{\mathrm{x}}(\mathrm{O}, \mathrm{N})_{\mathrm{y}}$ content in consolidated $\mathrm{ODS}-\mathrm{Fe}_{3} \mathrm{Al}$

5.2 Effect of milling conditions on alloy homogeneity

5.3 The effect of pre-consolidation sieving of ODS-Fe $\mathrm{Al}_{3}$ powder

6 Stimulation of interchange of non-confidential information, experience and materials

7 Conclusions

Acknowledgements

References

Distribution List

Research sponsored by the U.S. Department of Energy, Fossil Energy Advanced Research Materials Program, DOE/FE AA 151010 0, Work Breakdown Structure Element UL-2. 


\section{INTRODUCTION}

The work detailed within this report is a continuation of earlier work carried out under contract number 1DX-SY382V ${ }^{[1,2]}$ The earlier work comprises a literature review of the sources and types of defects found principally in Fe-based ODS alloys as well as experimental work designed to identify defects in the prototype ODS- $\mathrm{Fe}_{3} \mathrm{Al}$ alloy, deduce their origins and to recommend methods of defect reduction. The present work is an extension of the experimental work already reported and concentrates on means of reduction of defects already identified rather than the search for new defect types. This report also includes results gathered during powder separation trials, conducted by the University of Groningen, Netherlands and coordinated by the University of Liverpool, involving the separation of different metallic powders in terms of their differing densities.

The scope and objectives of the present work were laid out in the technical proposal 'Reduction in Defect Content in ODS Alloys - III'. All the work proposed in the 'Statement of Work' section of the technical proposal has been carried out and all work extra to the 'Statement of Work' falls within the context of an $\mathrm{ODS}-\mathrm{Fe}_{3} \mathrm{Al}$ alloy of improved overall quality and potential creep performance in the consolidated form. The outturn of the experimental work performed is reported in the following sections.

\section{DEFECTS AND THEIR ORIGINS}

As detailed in previous work, three main types of microstructural defect that may affect the alloy's properties occur within $\mathrm{ODS}-\mathrm{Fe}_{3} \mathrm{Al}^{.2]}$ Stringers of alumina particles populate the consolidated alloy alongside similarly orientated stringers of fine grains amongst the desired coarse secondary recrystallised grains. Within the $\mathrm{MA} \mathrm{ODS}-\mathrm{Fe}_{3} \mathrm{Al}$ powder particles are regions depleted in aluminium and oxide dispersoid that appear to pass through the consolidation process, manifesting themselves as inhomogeneities in the dispersoid distribution of the consolidated alloy. New findings regarding the origins and effects of these defects are discussed in the following sections. A fourth defect type occurs in the form of acicular precipitates throughout the consolidated alloy and is also discussed.

\subsection{STRINGERS OF $\mathrm{Al}_{\mathbf{x}}(\mathrm{O}, \mathrm{N})_{\mathrm{y}}$}

Generally, the particles of $\mathrm{Al}_{\mathrm{x}}(\mathrm{O}, \mathrm{N})_{\mathrm{y}}$ found throughout the ODS- $\mathrm{Fe}_{3} \mathrm{Al}$ are distributed in fairly dense stringers orientated parallel to the extrusion direction. Occasionally, however, the particles can be seen to describe distinct loops, completely encapsulating a small region of alloy. It is thought that these loops of alumina represent residual features of small MA powder particles that were covered in alumina scale and passed through the consolidation process whilst maintaining their form. ${ }^{[2,3]}$ At the high temperatures and pressures of the extrusion process, the scale has fractured and the particle sintered into the bulk alloy, leaving the fragmented scale in place. This gives some clue to the origin and morphological distribution of the remaining alumina particles, suggesting that they are the fragmented remnants of an oxide scale that formed on the MA powder before consolidation. Thus, as the powder was consolidated by an extrusion process, the fragmented oxide would generally be spread out into stringers elongated parallel to the extrusion direction or, as described above, survive the consolidation process almost completely intact with a shell of fragmented oxide.

This explanation for the origins of the oxide stringers is discussed in detail in Section 3.2. 


\subsection{REGIONS DEPLETED IN ALUMINIUM AND DISPERSOID}

Following MA, the dispersoid ought to be distributed homogeneously throughout the alloy, but the presence of dispersoid free areas suggests inadequate local powder milling. When powder particles were examined by FEG SEM, regions of chemical inhomogeneity were discovered, some as large as $\approx 100 \mu \mathrm{m}$ in diameter. ${ }^{[2]}$ These regions are thought to be fragments of the milling balls or attritor used in the MA process that have become entrained within the alloy powder particles. As such, they would not be expected to contain any YAG dispersoid.

When compared to commercially available ODS alloys, the MA ODS-Fe $\mathrm{AI}$ powder contained more chemical inhomogeneities. This may follow from higher powder hardnesses causing greater attrition of milling balls.

Samples of the largest sieved powder size fractions $(>425 \mu \mathrm{m})$ of batches PMWY1, 2 and 3 of the ODS-Fe ${ }_{3} \mathrm{Al}$ were mounted, sectioned and metallographically prepared to enable a crosscomparison of powder defect populations using SEM, since it had been reported that each batch of MA powder had been prepared using a different set of conditions during the original high energy ball milling process. ${ }^{[4]}$

It was found that the fraction sieved from alloy PMWY2 was similar to those already examined and reported earlier, with numbers of aluminium-depleted regions, as shown in Figure 1b, comprising $\approx 4 \mathrm{vol} \%$ of the powder. ${ }^{[2]}$ The over-size powder fraction sieved from PMWY1 essentially appeared to be identical to that of batch PMWY2, again containing aluminiumdepleted inhomogeneities (Figure 1a) to similar levels. Most of the aluminium-depleted regions were micron-sized and evenly distributed throughout the alloy, accounting for $\approx 2$ vol\%. However, alloys PMWY1 and 2 also contained significantly larger aluminium-depleted regions, tens of microns in size or larger, which contributed a further $\approx 2 \mathrm{vol} \%$ of inhomogeneities. The sieved fraction obtained from PMWY3, on the other hand, contained very few such large inhomogeneities, with only the finer distribution of aluminium-depleted material at levels of $\approx 2 \mathrm{vol} \%$ as seen in Figure 1 .
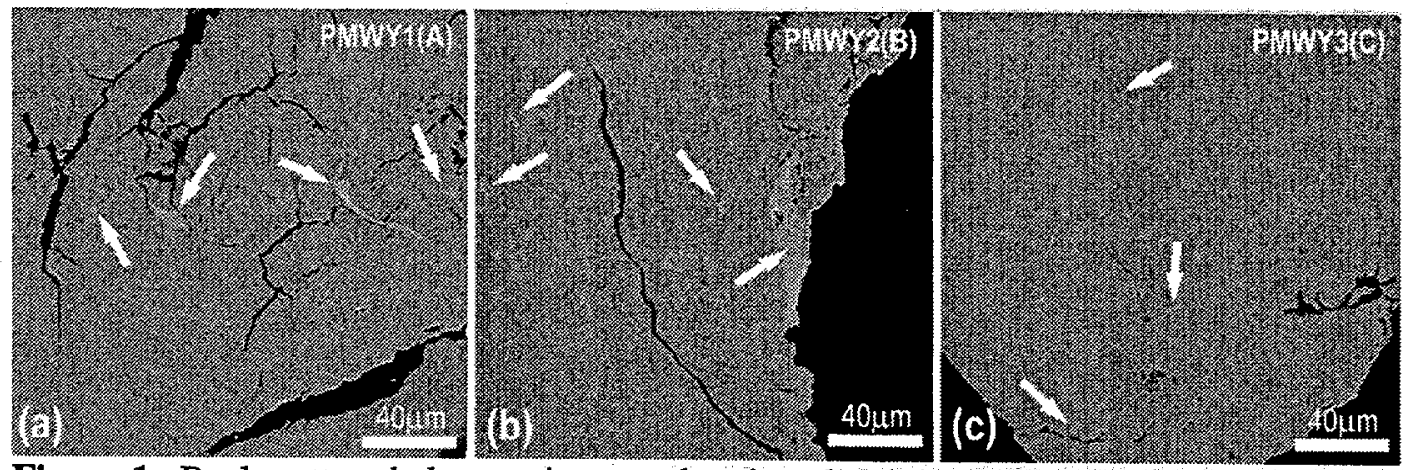

Figure 1 Backscattered electron images showing aluminium-depleted regions (arrowed) in alloys PMWY1, PMWY2 and PMWY3.

The only significant difference in the processing of PMWY3, according to the manufacturers, is that it was milled under vacuum. Such an environment will alter the balance in the powder welding/fracturing process that occurs during the initial stages in mechanical alloying. This may affect the characteristics of the layer of ODS-Fe $\mathrm{F}_{3} \mathrm{Al}$ that becomes welded to the surface of the hardened steel milling balls during the ball conditioning at the start of MA; and this may affect the extent to which the balls themselves are protected from the sort of attrition that leads to incorporation of Al-depleted material in the powders during MA. 


\subsection{FINE-GRAINED STRINGERS}

In both TEM and FEG SEM studies the outer edges of the fine-grained 'stringers' are often decorated with alumina particles or even delineated by stringers of the particles. This coincidence of grain boundaries and particles also occurs within the fine-grained regions and at grain boundaries in the secondary recrystallised material as shown in Figure 2. In primary recrystallised regions devoid of alumina the resultant grain size following recrystallisation is intermediate between that found in the remaining primary and the predominantly secondary recrystallised regions. It is unclear whether such regions represent the limit of normal grain growth of the primary grain structures in the absence of substantial particle pinning or, perhaps, imply recrystallisation of local, deformed primary grain structures to form regions of more conventional grain size ahead of the secondary recrystallisation front.

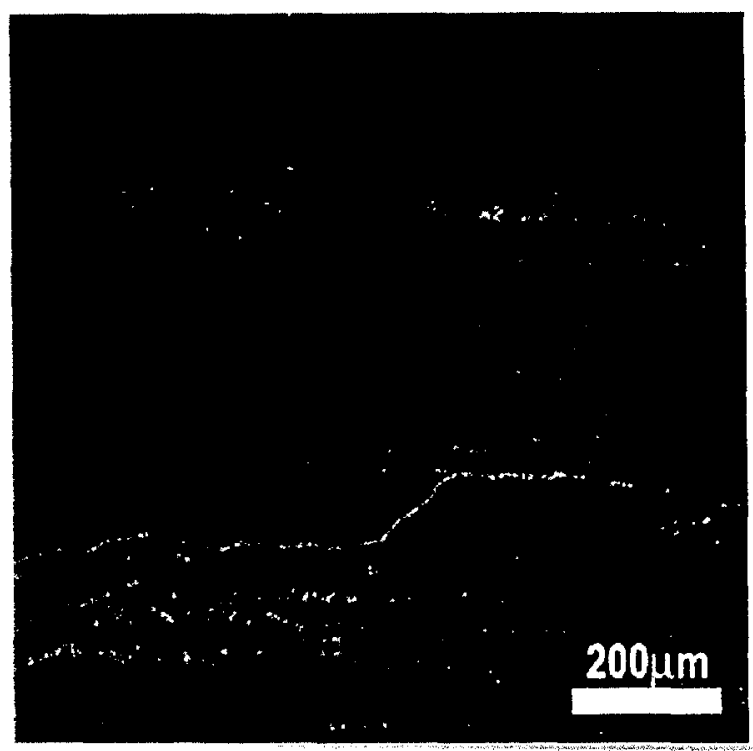

Figure 2 A polarization contrast micrograph showing the coincidence of stringers of $\mathrm{Al}_{\mathrm{x}}(\mathrm{O}, \mathrm{N})_{\mathrm{y}}$ particles (red/yellow) and grain boundaries in consolidated, secondary recrystallised $\mathrm{ODS}-\mathrm{Fe}_{3} \mathrm{Al}$ (green).

The pinning of boundaries in the ODS-Fe ${ }_{3} \mathrm{Al}$ is due principally to simple 'Zener' effects derived from the decrease in boundary energy caused by elimination of grain boundary area by pinning particles. As the alumina particles in this system are polycrystalline and originate prior to alloy consolidation and recrystallisation, they may be considered an incoherent phase. The maximum Zener drag may therefore be given by $9 V_{f} \sigma_{b} / 4 r$ for a flexible boundary, where $V_{f}$ is the volume fraction of particles, $r$ is the particle radius and $\sigma_{b}$ is the specific grain boundary energy. The large size of the alumina particles reduces their pinning efficacy and the fine YAG dispersoid would be expected to have a greater effect on boundary motion for comparable volume fractions. However, whereas the YAG dispersoid is generally evenly distributed throughout the alloy, the alumina particles tend to be concentrated in stringers, giving extremely high local volume fractions. In such regions, the factor $V f$ becomes significant and effective Zener pinning may occur.

In areas of the alloy free of YAG dispersoid, recovery will occur readily and the dislocation concentration will decrease during high temperature consolidation or the early stages of the secondary recrystallisation anneal. The juxtaposition of such areas with areas of higher dislocation density would provide a driving force for recrystallisation, the extent of which would be restricted if surrounded by alumina particles. Such areas would not readily be removed by growing, coarse secondary recrystallised grains and would contribute to retained fine-grained areas in the alloy. 


\subsection{ACICULAR PRECIPITATES}

These precipitates were reported some time ago but have not been the subject of intensive study as the previously described defect types are thought to be more likely to affect alloy properties and were therefore prioritised. ${ }^{[1]}$ However, some work has been conducted to identify the precipitates. Figure 3a shows a TEM micrograph of a portion of one of the acicular precipitates embedded within the bulk alloy in a sample of secondary recrystallised ODS-Fe $\mathrm{Al}$. Figures $3 \mathrm{~b}$ and $3 \mathrm{c}$ show a microdiffraction pattern from the precipitate and a selected area diffraction pattern from the bulk material respectively.
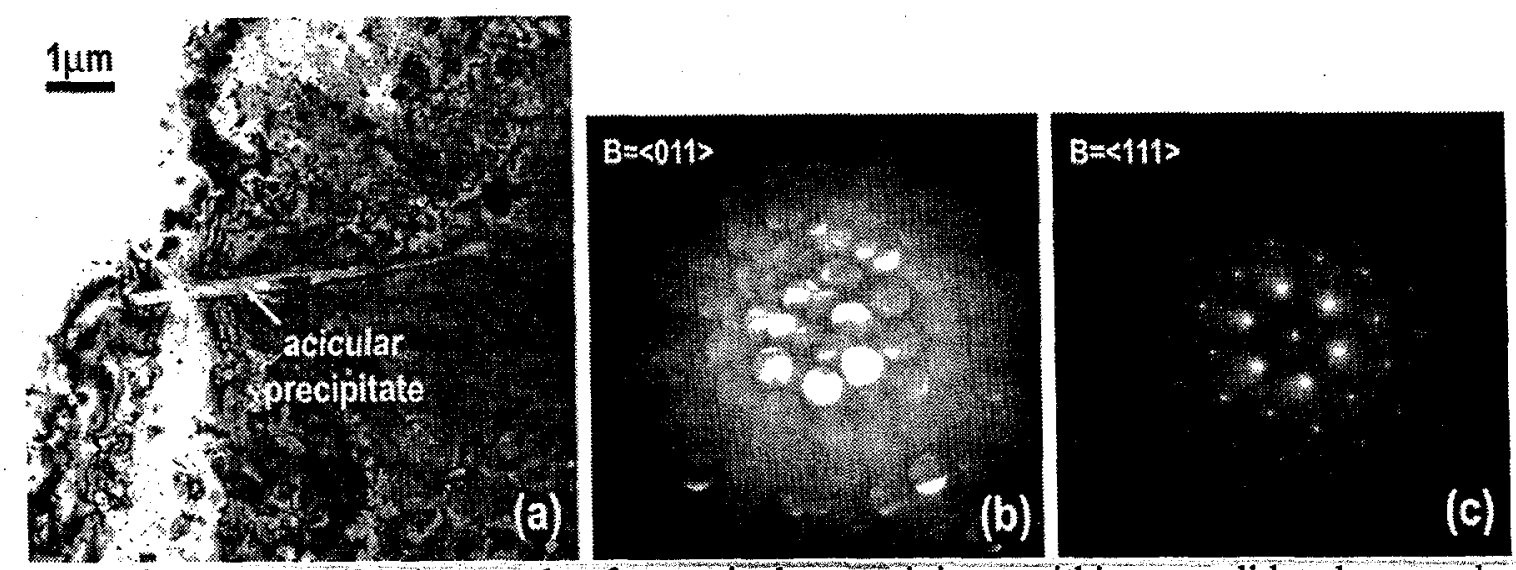

Figure 3

(a) TEM micrograph of an acicular precipitate within consolidated, secondary recrystallised $\mathrm{ODS}-\mathrm{Fe}_{3} \mathrm{Al}$ with diffraction patterns from (b) the precipitate and (c) the bulk alloy.

Analysis of the diffraction patterns shows that the ODS-Fe $\mathrm{Al}_{3} \mathrm{Al}$ bulk alloy has a body-centred cubic structure with a lattice constant of $2.94 \AA$ as might be expected. An ordered B2-type lattice has been observed in ODS-Fe $3 \mathrm{Al}$ but no ordering is apparent in this case. ${ }^{[5]}$ The precipitate, on the other hand, appears to have an ordered face-centred cubic (DO3) structure and a lattice constant of $3.80 \AA$.

EDS analysis of the precipitates has shown them to be identical in composition to the bulk alloy except for a slightly higher chromium concentration. ${ }^{[1]}$ It is tentatively proposed that the structure of the precipitates is linked to the higher chromium concentration, although this can not be substantiated at this stage.

\section{DEGASSING AND CONSOLIDATION HEAT TREATMENTS}

Before consolidation, the $\mathrm{ODS}-\mathrm{Fe}_{3} \mathrm{Al}$ powder undergoes two major vacuum heat treatments; one at $600^{\circ} \mathrm{C}$ for 1 hour in order to degas the powder and one at $1000^{\circ} \mathrm{C}$ for 1 hour immediately prior to consolidation to ensure that the whole powder charge has reached the consolidation temperature. These treatments are essentially similar to those used for existing commercial alloys and may therefore be receptive to modifications to make them more efficient for the ODS$\mathrm{Fe}_{3} \mathrm{Al}$ system. They may also have unforeseen effects on the powder charge, some of them deleterious to alloy properties.

\subsection{DEGASSING BEHAVIOUR OF ODS ALLOY POWDERS}

It has been shown in the literature that the recrystallisation state and defect concentration within an alloy may significantly influence the capacity of the alloy to absorb and desorb gas. ${ }^{[6]}$ The effects on the desorption properties are of particular interest in the context of degassing heat treatments for MA alloys as the temperatures used during the degassing process are of similar 
magnitude to the 1 hour recrystallisation temperatures of ODS- $\mathrm{Fe}_{3} \mathrm{Al}$ and PM2000 powder. In fact, the degassing temperature used for these two alloys, $600^{\circ} \mathrm{C}$, lies below the recrystallisation temperature of PM2000 $\left(\approx 775^{\circ} \mathrm{C}\right)$ but above that of $\mathrm{ODS}-\mathrm{Fe}_{3} \mathrm{Al}\left(\approx 575^{\circ} \mathrm{C}\right)$. The implication of this is that the PM2000 powder and ODS- $\mathrm{Fe}_{3} \mathrm{Al}$ powder may not be in similar microstructural conditions during degassing. The $\mathrm{ODS}-\mathrm{Fe}_{3} \mathrm{Al}$ is more likely to have undergone a greater degree of recovery and recrystallisation than the PM2000.

In order to investigate this possibility, both $\mathrm{ODS}-\mathrm{Fe}_{3} \mathrm{Al}$ and $\mathrm{PM} 2000$ powders were heated in a molybdenum boat in a high vacuum system at a range of temperatures, from $400^{\circ} \mathrm{C}$ to $800^{\circ} \mathrm{C}$, spanning the recrystallisation temperatures of both alloys. The amounts of hydrogen given off were measured using a VG Masstorr quadrupole mass spectrometer and the alloy powder temperature was monitored using a thermocouple immersed in the powder.

Accurate quantification of the tiny amounts of gas given off during heating has proved difficult with the present apparatus. However, comparative measurements of gas evolved reconfirmed that up to ten times as much hydrogen was released from PM2000 as from ODS-Fe ${ }_{3} \mathrm{Al}$. This finding is in line with previous work. ${ }^{[2]}$

Also in agreement with previous work, it was found that the temperature at which degassing was performed had a significant effect on the degassing kinetics within the first few minutes. However, it had little effect on the overall amount of hydrogen evolved over 10-15 minutes. That is to say that at higher temperatures the hydrogen pressure peaked at a high value but then decayed rapidly whereas at lower temperatures the peak was not as high but decayed more slowly. The integrated amounts of hydrogen were therefore similar in both cases.

It would therefore appear that the relative magnitudes of the degassing temperature and the alloys' recrystallisation temperatures are not important over the lengths of time (several minutes) during which evolution of the bulk of the hydrogen takes place.

Work presently in progress involves measuring the amounts of hydrogen remnant in the ODS$\mathrm{Fe}_{3} \mathrm{Al}$ and $\mathrm{PM} 2000$ powders after degassing heat treatments at various temperatures as an alternative means of measuring the degassing efficiency of different systems.

\subsection{PRECONSOLIDATION HEAT TREATMENTS AND POWDER OXIDATION}

It has already been reported that the prototype $\mathrm{ODS}-\mathrm{Fe}_{3} \mathrm{Al}$ contains large numbers of defects, particularly in the form of high concentrations of $\mathrm{Al}_{\mathrm{x}}(\mathrm{O}, \mathrm{N})_{\mathrm{y}}$ particles throughout the consolidated alloy and in fine-grained regions within the coarse-grained secondary recrystallised microstructure. $^{[2]}$ Previously, evidence has been presented showing how fine-grained regions may result from interaction of secondary recrystallising grain boundaries with stringers of $\mathrm{Al}_{\mathrm{x}}(\mathrm{O}, \mathrm{N})_{\mathrm{y}}$ and dispersoid-free areas. ${ }^{[3]}$ Such defects do not occur to a significant extent in the alloy PM2000 which was, therefore, used as a benchmark alloy throughout this work.

In order to compare the propensity of $\mathrm{ODS}-\mathrm{Fe}_{3} \mathrm{Al}$ and $\mathrm{PM} 2000$ powders to oxidise under high temperature, low oxygen environments, such as those employed during commercial canning and consolidation of these alloys, small amounts of both powders were heated concurrently under a vacuum of $\approx 10^{-3}$ mbar in a partitioned tantalum boat. This ensured that, even if the experimental conditions were not a faithful representation of commercial techniques, a valid comparison could be made between the oxidation behaviour of the two alloys. This process was performed twice, once at $600^{\circ} \mathrm{C}$ and once at $1000^{\circ} \mathrm{C}$. The annealing temperatures were chosen to simulate the degassing heat treatment at $600^{\circ} \mathrm{C}$ and the pre-consolidation high temperature 'soak' at $1000^{\circ} \mathrm{C}$ that the canned MA powder undergoes before consolidation.

The surface of the powders was examined by Scanning Electron Microscopy (SEM) while still in the boat and Figure 4 shows such powders after annealing at $1000^{\circ} \mathrm{C}$. Even at such low magnification, the greater extent of oxidation of the $\mathrm{ODS}-\mathrm{Fe}_{3} \mathrm{Al}$ was apparent through brighter $\mathrm{SEM}$ images of the $\mathrm{ODS}-\mathrm{Fe}_{3} \mathrm{Al}$ powders, caused by charging and work-function effects associated with a greater thickness of oxide scale. This effect was not seen after annealing at 
$600^{\circ} \mathrm{C}$. Subsequently, specimens of annealed powders were mounted in resin and metallographically sectioned so that oxide scale thickness could be determined in the SEM. In the powders annealed at $600^{\circ} \mathrm{C}$ no significant oxidation had taken place, whereas a scale was clearly visible on the powders annealed at $1000^{\circ} \mathrm{C}$. One hundred measurements were made of the scale thickness on each alloy. A plot of the oxide scale thickness distribution for both ODS$\mathrm{Fe}_{3} \mathrm{Al}$ and PM2000 is shown in Figure 5 as measured from SEM micrographs such as those shown in Figure 6 . Figure 5 reveals that while PM2000 exhibits a narrow distribution of mainly submicron thickness scale, the ODS-Fe ${ }_{3} \mathrm{Al}$ exhibits a much broader range that includes scale up to several microns in thickness. It would appear, therefore, that the origin of the higher volume fractions of $\mathrm{Al}_{\mathrm{x}}(\mathrm{O}, \mathrm{N})_{\mathrm{y}}$ found in the consolidated $\mathrm{ODS}-\mathrm{Fe}_{3} \mathrm{Al}$ may well derive from oxide scale that forms on the powder particles during pre-consolidation annealing; specifically, the high temperature annealing of the powder immediately prior to consolidation. Moreover, this explanation of excess oxide formed at powder particle surfaces is consistent with the not infrequent observation of a 'necklace' distribution of some of the $\mathrm{Al}_{\mathrm{x}}(\mathrm{O}, \mathrm{N})_{\mathrm{y}}$ seen in sections of consolidated bar. ${ }^{[3]}$ Given this origin, then a reduction in pre-consolidation oxidation by appropriate controls should decrease the incidence of oxide stringer defects in consolidated ODS-Fe ${ }_{3} \mathrm{Al}$.
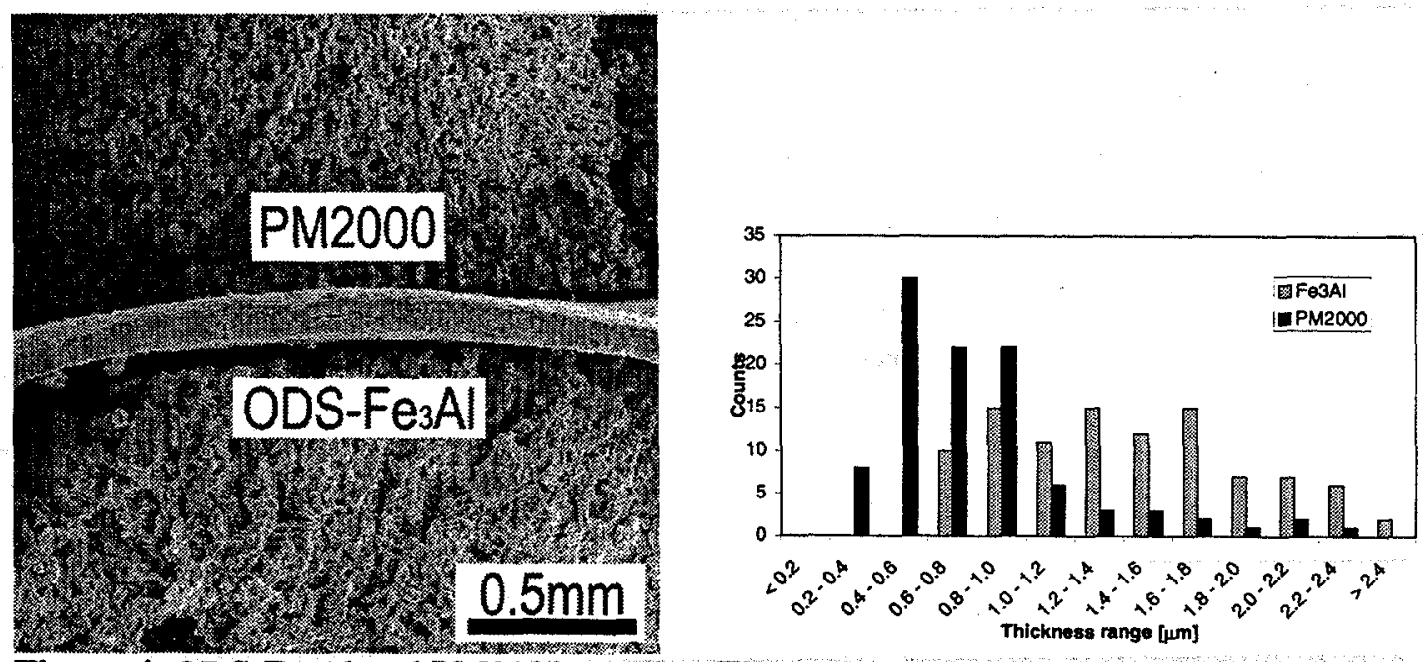

Figure $4 \mathrm{ODS}-\mathrm{Fe}_{3} \mathrm{Al}$ and PM2000 powder Figure 5 Oxide scale thickness distributions for annealed at $1000^{\circ} \mathrm{C} / 1$ hour $/ 10^{-3} \mathrm{mbar}$. ODS-Fe $\mathrm{O}_{3} \mathrm{Al}$ and PM2000.

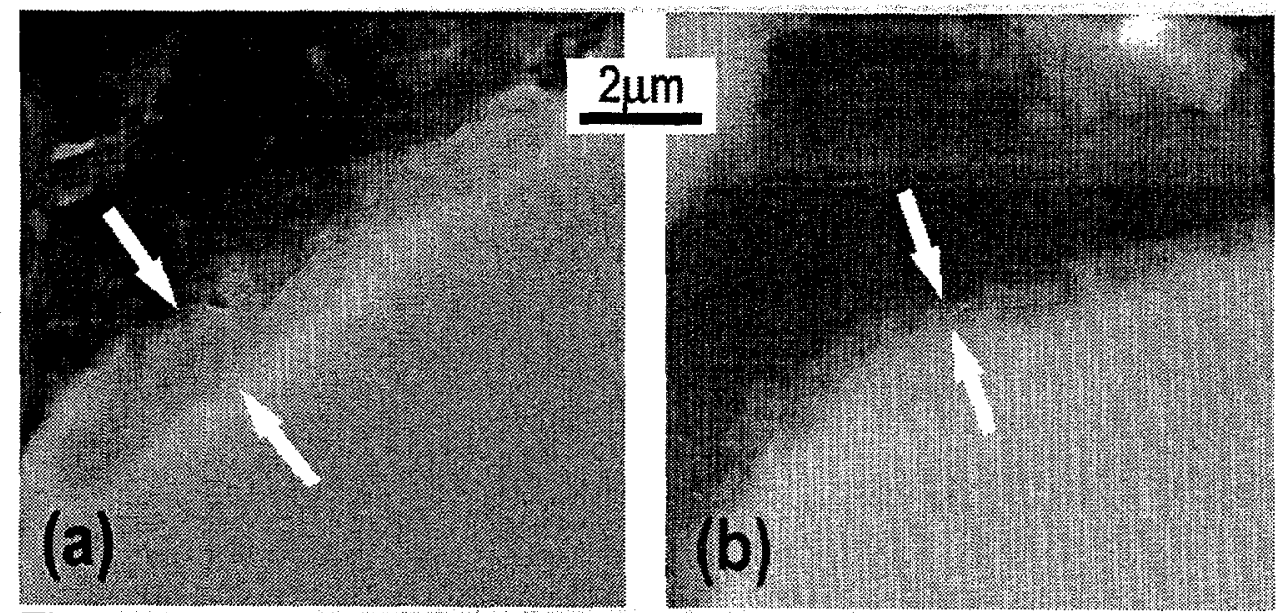

Figure 6 SEM micrographs showing the oxide layer formed on (a) ODS$\mathrm{Fe}_{3} \mathrm{Al}$ and (b) PM2000 after annealing at $1000^{\circ} \mathrm{C}$ for 1 hour under a vacuum of $10^{-3}$ mbar. 


\subsection{HYDROGEN PURGING TO REDUCE POWDER OXIDATION}

With a view to reducing powder oxidation, hydrogen purging of the vacuum system and powder was investigated as a possible palliative measure. In order to more accurately represent oxidation of powders in a commercial heat treatment environment, miniature, mild steel cans (6mm diameter, $15 \mathrm{~mm}$ height) were prepared and filled with either ODS-Fe ${ }_{3} \mathrm{Al}$ or PM2000, then annealed for 1 hour at $1000^{\circ} \mathrm{C}$ under a vacuum of $\approx 10^{-3} \mathrm{mbar}$, as might be applied in the case of a typical consolidation procedure. Two cans, one containing ODS-Fe ${ }_{3} \mathrm{Al}$ and one PM2000 as shown in Figure 7, could be concurrently heat-treated first without hydrogen purging to simulate typical current consolidation practice and then, with a fresh charge of as-MA powders, after purging the system with hydrogen. Purging involved the ambient evacuation of the system and two cycles of refilling to atmospheric pressure with hydrogen followed by re-evacuation. During all annealing experiments powder sintering took place and the resulting sintered powders were examined by means of SEM, EDS and compressive testing.

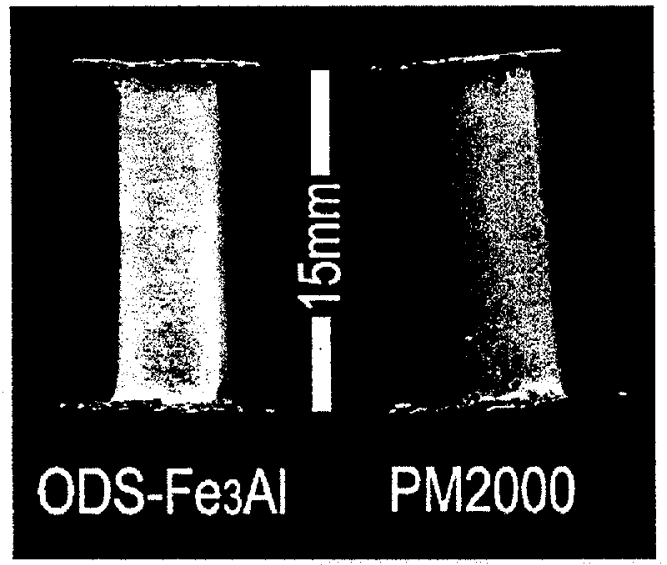

Figure 7 The miniature mild steel cans used to contain $\mathrm{ODS}-\mathrm{Fe}_{3} \mathrm{Al}$ and $\mathrm{PM} 2000$ powder during the hydrogen purging experiments.

As can be seen in the superimposed EDX spectra obtained from the surface of annealed ODS$\mathrm{Fe}_{3} \mathrm{Al}$ powders shown in Figure 8, the effect of hydrogen purging was to reduce levels of oxidation, evidenced by the reduced oxygen and aluminium peak heights. Hydrogen purging also had a significant effect on the extent of powder sintering during annealing. Figure 9, which reflects results of post-sintering, ambient compressive tests on 'de-canned' powders, illustrates two effects (note logarithmic stress scale). The first is that the compressive sinter strength of annealed, un-purged PM2000 is approximately two orders of magnitude higher than in $\mathrm{Fe}_{3} \mathrm{Al}$.

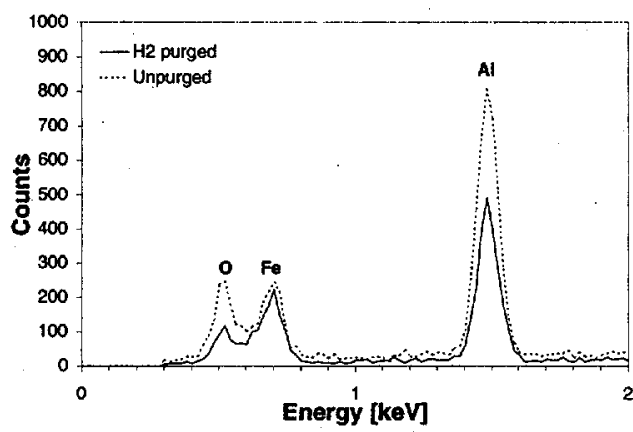

Figure 8 EDS spectra showing the reduction of oxide formation by hydrogen purging of $\mathrm{ODS}-\mathrm{Fe}_{3} \mathrm{Al}$ powder.

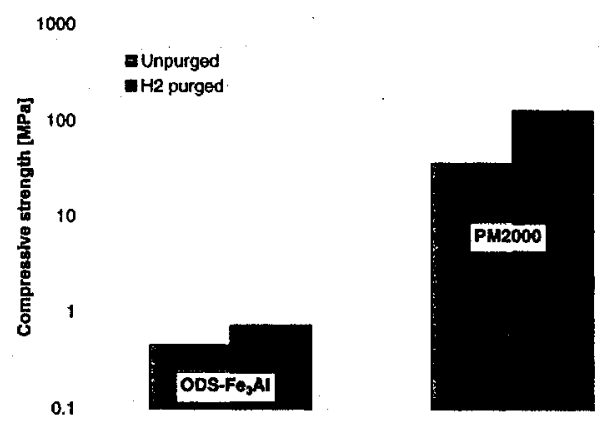

Figure 9 The effect of hydrogen purging on sintered compressive strength.

This is presumably due to the formation of relatively large amounts of oxide scale on the ODS$\mathrm{Fe}_{3} \mathrm{Al}$ powder that inhibits metal-to-metal contact and in-situ sintering. The lower levels of 
oxidation found on PM2000 do not appear to retard sintering to the same extent. The second effect is the large increase in the sinter strengths of both powders following hydrogen purging. The percentage increases were $61 \%$ and $255 \%$ for the ODS-Fe $3 \mathrm{Al}$ and the PM2000, respectively
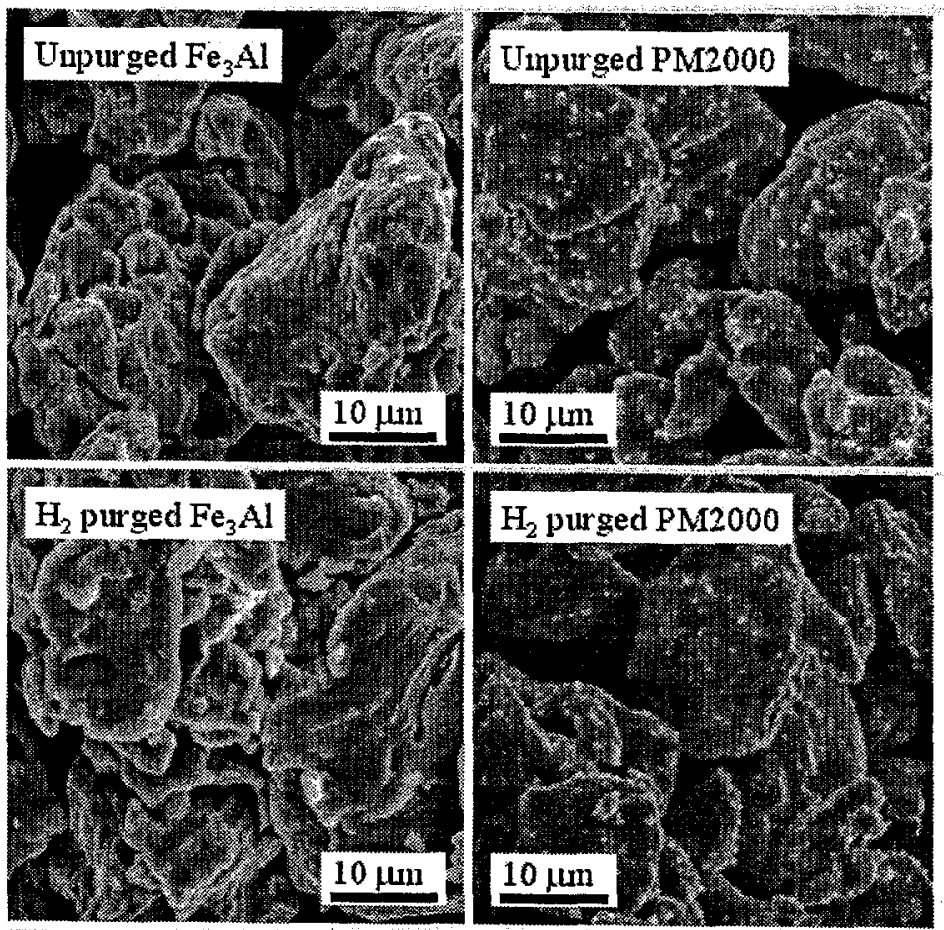

Figure 10 SEM micrographs of powder particles of ODS-Fe $3 \mathrm{Al}$ and PM2000 after annealing at $1000^{\circ} \mathrm{C}$ for 1 hour under $10^{-3}$ mbar without and with hydrogen purging.

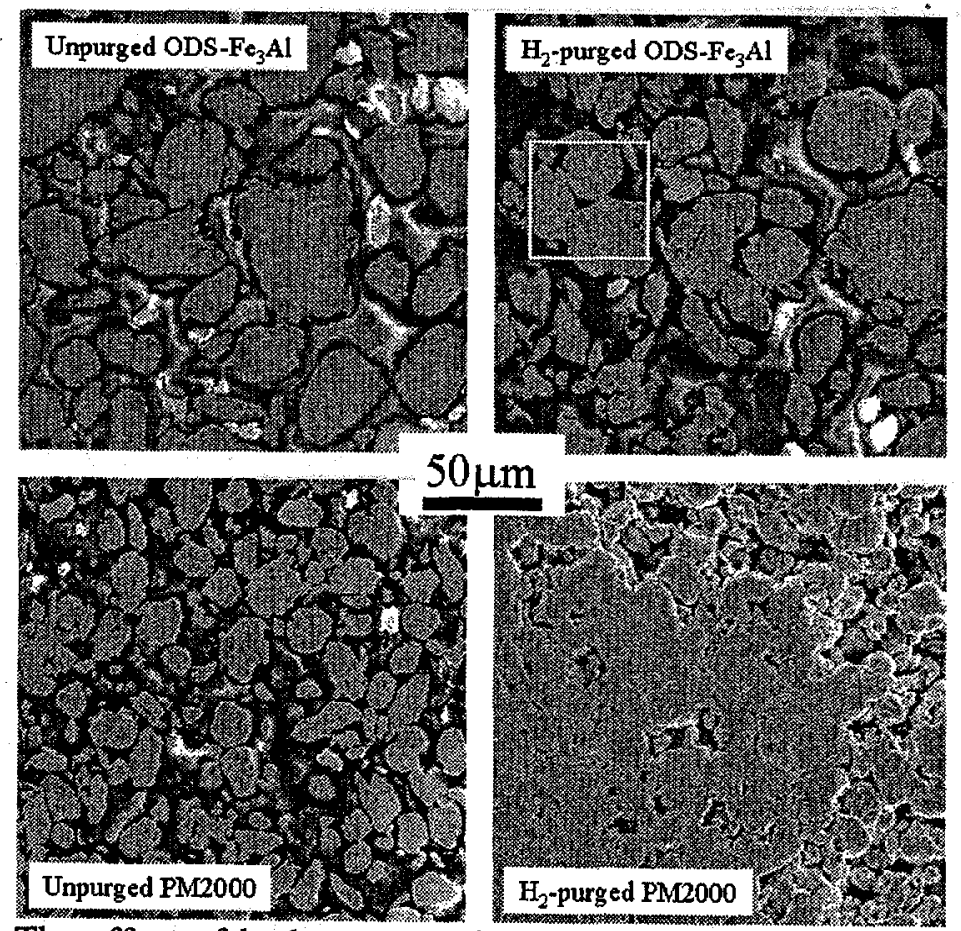

Figure 11 The effect of hydrogen purging on the sintered density of ODS-Fe ${ }_{3} \mathrm{Al}$ and PM2000 powder 
It is not clear why the sintering efficiency (as reflected in the increased compressive strength) has increased more in the PM2000 than in the ODS-Fe $3 \mathrm{Al}$, although the reduction in oxidation caused by hydrogen purging may have had more significance when applied to the thinner oxides found on PM2000. This view is supported by evidence revealed in Figure 10 which shows the differences in oxidation behaviour of ODS-Fe ${ }_{3} \mathrm{Al}$ and PM2000 both without and with hydrogen purging. It can be seen that whereas the ODS-Fe ${ }_{3} \mathrm{Al}$ particles form a continuous oxide layer of significant thickness, the PM2000 particles form islands of oxide surrounded by an oxide of negligible thickness. Hydrogen purging causes a clear reduction in the extent of oxidation of the PM2000 while having little obvious effect on that of the ODS- $\mathrm{Fe}_{3} \mathrm{Al}$.

The relative effectiveness of hydrogen purging on sintering efficiency can be seen in Figure 11, which shows metallographic sections of sintered ODS-Fe ${ }_{3} \mathrm{Al}$ and PM2000, with and without hydrogen purging. While some enhanced neck formation is apparent in the ODS-Fe $\mathrm{Al}$ after purging (e.g. boxed on figure), extensive sintering has occurred in the PM2000, reflecting the compressive strength data for the two alloys.

\subsection{COLD COMPACTION TO REDUCE POWDER OXIDATION}

As a further means to reduce the amount of oxidation occurring during pre-consolidation annealing, ODS- $\mathrm{Fe}_{3} \mathrm{Al}$ powder was cold compacted before heat treatment in an attempt to reduce the free surface area of the powder and to promote sintering.

The ODS- $\mathrm{Fe}_{3} \mathrm{Al}$ powder was uniaxially compressed into a cylindrical die (ID $10 \mathrm{~mm}$ ) at a pressure of $635 \mathrm{MPa}$ to produce a green compacted pellet of $\approx 4 \mathrm{~mm}$ height. This pellet was annealed at $1000^{\circ} \mathrm{C}$ under a vacuum of $\approx 10^{-3}$ mbar for 1 hour, within its die to simulate canning, and was then studied by SEM and compressive testing and compared to a similarly heat-treated powder that had not been compacted prior to heating.

Compaction clearly leads to an increase in sintering efficiency as would be expected. The strength of the sintered ODS-Fe $\mathrm{Fl}_{3} \mathrm{Al}$ powder increased 120 fold as shown in Figure 12. It should be noted, however, that this substantial increase in compaction strength only brings ODS-Fe $\mathrm{Al}$ to a level equivalent to that seen in PM2000 powder annealed without compaction or hydrogen purging. This difference is almost certainly due to the small amount of oxidation of PM2000, as it is not believed that there is a great difference in the degree of loose packing between ODS$\mathrm{Fe}_{3} \mathrm{Al}$ and $\mathrm{PM} 2000$.

The effect of greater significance to this study is the reduction of free surface area by compaction and the resulting enhanced sintering. The metallographic sections in Figure 13 illustrate the substantial reduction in free surface available for oxide growth in the compacted and heat treated powders compared with the unpressed powders.

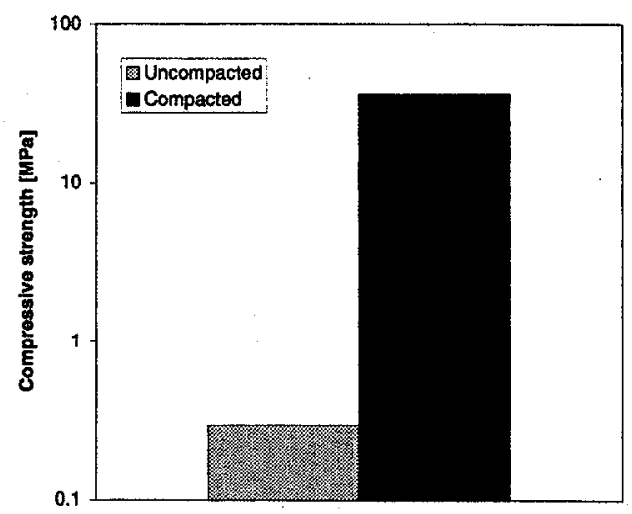

Figure 12 The effect of cold compaction on the sintered compressive strength of ODS-Fe $\mathrm{F}_{3} \mathrm{Al}$.

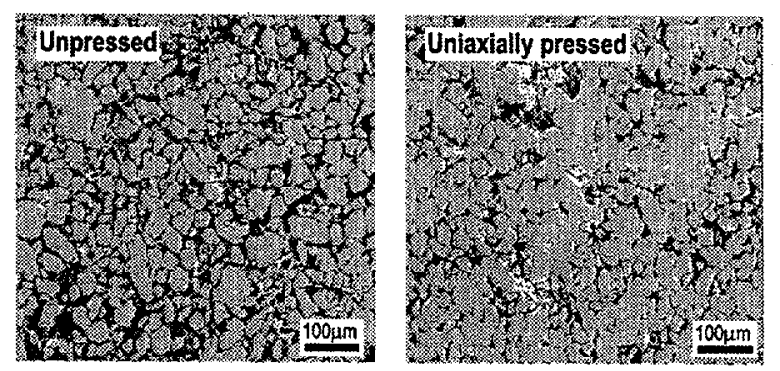

Figure 13 The effect of cold compaction on the density of sintered ODS-Fe $\mathrm{F}_{3} \mathrm{Al}$. 
This evidence, while circumstantial, suggests that suitable cold compaction prior to high temperature consolidation annealing could lead to a reduction in the amount of oxide both forming on $\mathrm{ODS}-\mathrm{Fe}_{3} \mathrm{Al}$ powders and being entrained in the consolidated alloy. If an increase in sintered strength is a simple indicator of the potential of this process modification, it appears that, for $\mathrm{ODS}-\mathrm{Fe}_{3} \mathrm{Al}$, under the vacuum conditions employed, compaction is a more effective palliative than hydrogen purging.

\section{POWDER SEPARATION TECHNIQUES}

It is clear that some of the defects found in consolidated MA alloys may have originated from inhomogeneities in individual powder particles introduced during MA processing; and that some such defective powders may be distinguished from the bulk by differences in density. Moreover, a possible means to extricate such powders from the bulk prior to consolidation may be found in recent advances in fluidised bed powder separation techniques. In the present work, fluidised bed experiments devised to explore the possibility of powder separation on the basis of differences in powder density were performed at the University of Groningen, Netherlands by C. Dechsiri and A.C. Hoffmann (see 'Acknowledgements').

\subsection{THE FLUIDISED BED SEPARATION TECHNIQUE}

\section{Fluidisation}

Fluidisation is a process that is common in many industries such as oil refining and the food and pharmaceutical industries, etc. There are many different applications of fluidisation in industry nowadays, for instance for granulation, coating, mixing, drying, catalytic cracking and recycling. Depending on the bed material, a bed will bubble at a given aeration rate, and a fraction of the gas will effectively by-pass the bed in the fluidisation bubbles (see Figure 14). If there is particle inflow and outflow ('continuous' beds), the bed will act as an ideal mixer unless the aeration rate is kept very low. If a mixture of particles is present, the heavier and/or larger ones will tend to sink. The severity of this effect depends on the particle properties and the aeration rate.

\section{Fluidisation and separation}

The heavier and/or larger particles tend to sink in fluidised beds. This can be a problem, since segregation can lead to defluidisation in the bottom of the bed, causing costly process downtime. On the other hand, segregation can be utilized if a particulate product can be brought to collect somewhere in the bed to be withdrawn preferentially. Another use of segregation is for classification of particles, for instance, in recycling. The application of fluidised beds for separation is not a new technology, though has not previously been applied to the current problem.

\section{Fluidisation with internals}

During a research project in Particle and Dispersed Phase Technology at the University of Groningen (RuG), where particle dynamics in fluidised beds was investigated, it was found that the natural tendency for segregation could be enhanced by incorporating a series of sieve-like baffles in the bed such as those shown in Figure 15, as indicated in Figure 14. ${ }^{[7,8]}$

The baffles had a large open area, and an aperture size much larger than the bed particles. Figure 16 shows the effect of baffles on the jetsam concentration-profile in a fluidised bed containing a mixture of different-sized glass beads. The phenomenon of segregation is non-linear in nature: 
once it has started, it will lead to a decrease in bubble activity low in the bed, in turn further decreasing the mixing, enhancing the segregation.

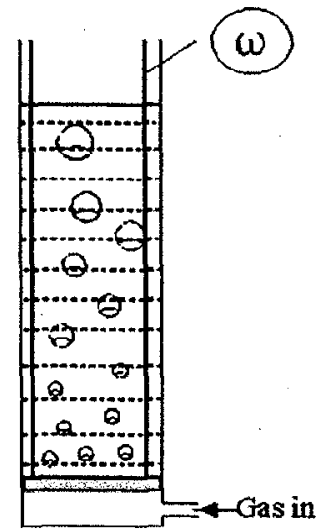

Figure 14 Fluidised bed where vibration $(\omega)$ is applied to the baffles during fluidisation.

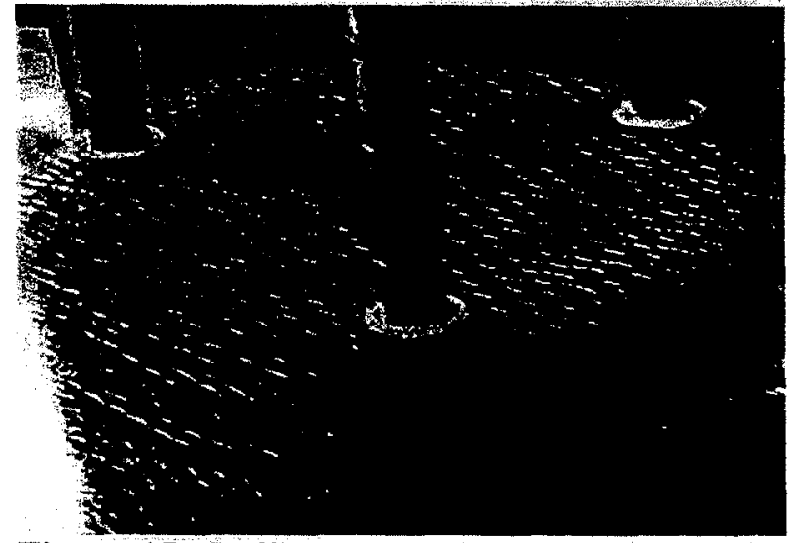

Figure 15 Baffle construction with $0.43 \mathrm{~cm}$ separation between the baffles.

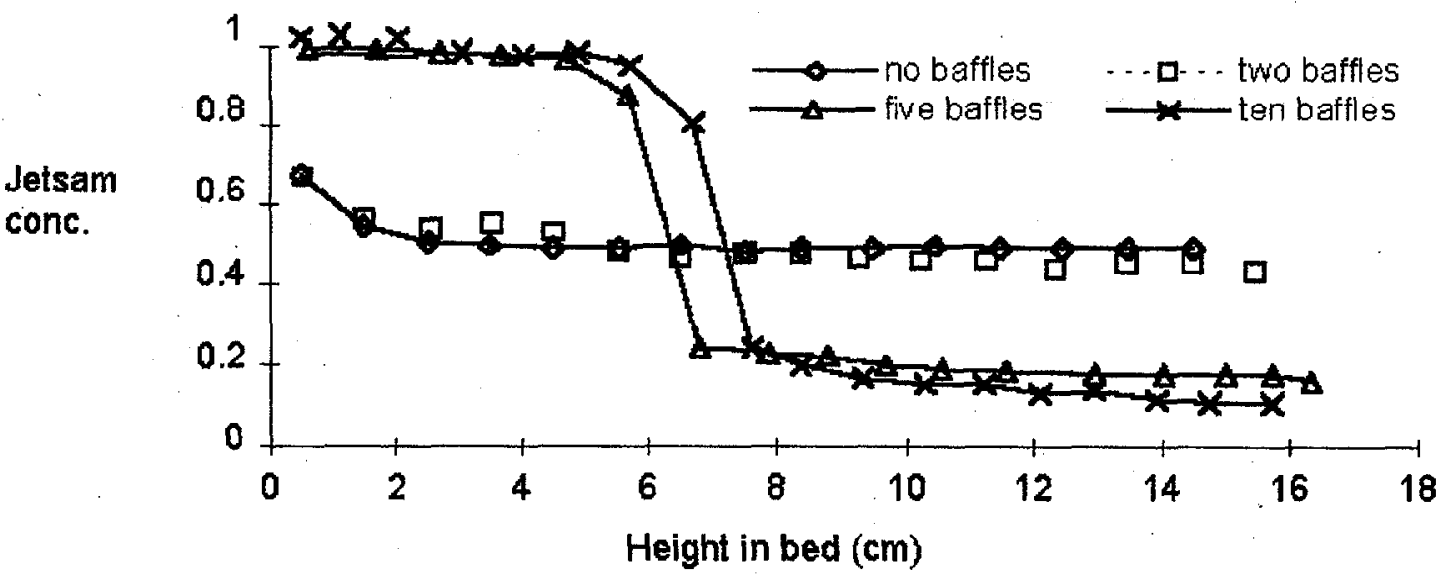

Figure 16 The effect of baffles on the concentration profile of jetsam in a 50:50(vol.) mixture of glass beads of about 250 and $500 \mu \mathrm{m}$ in diameter.

The key mixing process in bubbling fluidised beds is the upward transport of jetsam (particles naturally tending to sink) in the wakes of rising bubbles. The baffles decrease mixing, and thus enhance segregation, by knocking out part of the bubble wakes. Research using baffles in binary mixtures has already proven that such baffles boost segregation. For instance, figure 16 shows the effect of baffles on the concentration profile of jetsam in $50 \%$ vol. mixture of glass beads, about 500 and 250 micron in diameter : the more baffles, the better the segregation.

More experimental results on fluidisation with baffles can be found in an article "Stochastic model for particle mixing and segregation in fluidised beds with baffles". [9]

\section{Fluidisation with vibrating internals}

Applying vibration to the bed is known to improve fluidisability and break interparticle bonds even on the small scale. The underlying principle is that the vibrations decrease the bond strength of the bulk material, thereby increasing its ability to flow. The problem with this method is that the shock waves from the vibration only travel some centimetres into the bed before they are attenuated, leaving much of the bed unimproved. 
In the Particle and Dispersed Phase Technology group at RuG a new principle has been developed. In order to cause the shock waves to penetrate the entire bed, vibration is applied to an internal structure spanning the bed, rather than only applying vibration to the bed-containing vessel or the gas distributor plate. In the following experiments a baffle-module was used, as shown in Figure 8, but any structure can be used. More details can be found elsewhere. ${ }^{[10]}$

\subsection{SEPARATION OF SEED POWDERS FROM IRON-BASED POWDER}

In order to ascertain whether or not the fluidised bed separation technique had potential to separate metallic powders in terms of their density, a series of trials was devised to quantitatively measure the degree to which density separation was feasible. Rather than using random batches of MA powder, a controlled batch of powder was assembled such that the only variable throughout the powder was alloy density. Sieved, spherical, gas-atomised powders were obtained with a size distribution of $75-106 \mu \mathrm{m}$. The compositions and densities of the powders used are shown in Table 1. Using the iron-copper powder as the bulk of the batch, RuG systematically added the other 'seed' powders and then strove to remove them on the basis of their density difference relative to the bulk powder.

Table 1 Compositions and densities of powder used in the separation trials

\begin{tabular}{|c|c|c|}
\hline Composition [wt\%] & Density [g.cm ${ }^{-3}$ ] & Mass used [kg] \\
\hline $\mathrm{Fe}-13 \mathrm{Cu}$ & 8.02 & 8.0 \\
\hline $\mathrm{Cu}-10.3 \mathrm{Al}-5.6 \mathrm{Ni}-4.5 \mathrm{Fe}-1.1 \mathrm{Mn}$ & 8.25 & 0.2 \\
\hline $\mathrm{Cu}$ & 8.96 & 0.2 \\
\hline $\mathrm{Ni}-3.4 \mathrm{Si}-1.2 \mathrm{~B}-1.1 \mathrm{Fe}$ & 8.59 & 0.2 \\
\hline $\mathrm{Cu}-0.53 \mathrm{Ti}$ & 8.93 & 0.2 \\
\hline $\mathrm{Fe}-6.1 \mathrm{~W}-4 \mathrm{Cr}-3.9 \mathrm{Mo}-1.9 \mathrm{~V}-0.9 \mathrm{C}$ & 8.60 & 0.2 \\
\hline $\mathrm{Al}$ & 2.70 & 0.2 \\
\hline
\end{tabular}

The experiments were carried out in a glass column of $15-\mathrm{cm}$ diameter. The relative humidity of fluidising air was kept at approximately $30 \%$. The baffles used consist of woven wires of $0.65-$ $\mathrm{mm}$ diameter with weave of $0.42-\mathrm{cm}$ giving $71.1 \%$ open area, and were attached to three tierods. The spacing between the baffles was $0.43 \mathrm{~cm}$.

A typical experiment was started at a high gas velocity at which the bed was well mixed. The baffles were inserted, the gas velocity reduced to the required level, and the vibration applied to the system. Every experiment using the vibrating baffles was performed at the minimum amplitude of $0.5 \mathrm{~mm}$ and at a frequency of around $15 \mathrm{~Hz}$.

The bed was allowed to reach a steady state and then the air supply was cut off suddenly in order to freeze the powder distribution. Sectioning of the bed was performed using a traditional vacuum technique that allowed the removal of material in layers down to $1 \mathrm{~mm}$ in thickness.

To date, separation of the aluminium powder and the copper-based powders has been studied as these 'seed' powders represent the greatest density differences relative to the bulk iron-copper powder.

Separation of the aluminium powder yielded a visible layer at the top of the bed that could be removed for analysis before another sample was taken of the topmost underlying powder. An EDS survey of 100 particles from each of the powder samples showed that the visible powder layer contained $93 \mathrm{vol} \%$ aluminium and the slightly lower sampled layer contained $35 \mathrm{vol} \%$ aluminium. If the bulk aluminium concentration is taken to be approximately $2 \mathrm{vol} \%$, it can be seen that extremely efficient separation has taken place when using aluminium, the least dense powder.

Separation of the copper powder yielded no such visible layer and sampling was performed blind from the top and bottom of the fluidised bed. Results obtained regarding the degree of separation are less conclusive than those collected from the aluminium separation. This might be 
expected considering that the difference in densities of the copper powder and the bulk power is $\approx 12 \%$ as opposed to $\approx 66 \%$ for the aluminium powder and bulk powder. Two different techniques were used to assess the degree of separation. Although both imply that separation of copper powders has, indeed, taken place, the data are not consistent. An EDS survey of 200 particles from each sample shows that the concentration of copper at the top of the bed was $0.5 \mathrm{vol} \%$ whereas the concentration at the bottom of the bed was $1.5 \mathrm{vol} \%$. This seems to show that separation has occurred but the fact that the concentrated copper layer at the bottom of the bed contains less than the overall concentration of copper $(\approx 2 \mathrm{vol} \%)$ casts some doubt on the accuracy of the data. Image analysis of metallographic sections of mounted powder samples suggests that the concentrations at the top and bottom of the bed are $4.55 \mathrm{vol} \%$ and $6.33 \mathrm{vol} \%$ respectively. Again, separation appears to have taken place, and in the same sense, but here both values are higher than the bulk concentration. It is tentatively proposed that separation of the copper powder from the bulk iron-copper powder has occurred to a limited extent but that further work is needed on quantification of the data. Moreover, further work needs to be undertaken to ensure methods of removing samples from powder beds are as selective and efficient as possible and on bed fluidisation with optimised frequency and amplitude of bed vibration.

The separation trials, involving the gas atomised $\mathrm{Cu}$ powder in a bed of $\mathrm{Fe}-\mathrm{Cu}$ are important because Al-free powders (see section 2.2) will have a maximum density difference compared to ODS $\mathrm{Fe}_{3} \mathrm{Al}$ of $120 \%$. This suggests that if the $\mathrm{Cu}-\mathrm{Fe}-\mathrm{Cu}$ fluidisation experiment can be successfully refined then there is a reasonable possibility that similar methods may be applied successfully to separate some of the worst examples of dispersoid-free powders from bulk asMA ODS $\mathrm{Fe}_{3} \mathrm{Al}$.

\section{PRODUCTION SCHEDULES FOR LOWER DEFECT ODS ALLOYS}

This section of the report summarises relevant material from preceding sections, placing them in the context of commercial production schedules, and suggests how findings may be applied during alloy powder manufacture to achieve lower defect levels.

Also, new data are presented regarding the results of trials conducted by ORNL to assess the benefits of production schedule modifications suggested in a previous report. ${ }^{[2]}$

\subsection{REDUCTION OF $\mathrm{Al}_{\mathbf{x}}(\mathrm{O}, \mathrm{N})_{\mathbf{y}}$ CONTENT IN CONSOLIDATED ODS-Fe $\mathrm{e}_{3}$}

It has been shown that the origin of the high $\mathrm{Al}_{\mathrm{x}}(\mathrm{O}, \mathrm{N})_{\mathrm{y}}$ particle content of $\mathrm{ODS}-\mathrm{Fe}_{3} \mathrm{Al}$ is oxide scale formed on the alloy powder particles during high temperature treatments conducted immediately prior to the consolidation process. Two techniques have been demonstrated in the laboratory to significantly reduce the formation of such a scale and the deleterious effects it may have on powder sintering efficiency. The techniques are hydrogen purging of the powder and cold compaction of the powder before high temperature annealing.

Purging of powder charges with hydrogen is considered to be a viable introduction to commercial powder production for a number of reasons.

- The use of hydrogen as a reducing agent for the inhibition of metal oxidation is a 'tried and tested' method for which there exists a broad base of knowledge and a long commercial history.

- As MA powder production often already uses hydrogen as a cover gas, the resources required for the large scale use of hydrogen already exist.

- It has been shown to have a beneficial effect on alloy properties for at least two alloys and it is believed that it could be applied to many more. 
Cold compaction would involve the introduction of an extra stage in the powder production process where the powder is pressed by some means. However, the indications are that it too shows commercial potential.

- the powder compaction stage could utilise existing pressing (e.g. CIP) technology.

- There ought to be considerable flexibility in choice of compaction method as even simple, uniaxial pressing has been shown to be effective and oxidation data implies that compaction could be conducted at temperatures up to at least $600^{\circ} \mathrm{C}$ without significant powder oxidation taking place.

- A compaction process ought to be applicable to any powder system prone to oxidation.

- Powder compaction improves particle contact and, thereby, the conductivity of the powder charge. Subsequent heat treatments may therefore be shortened in duration as the heating rate of powder at the centre of the charge increases.

\subsection{THE EFFECT OF MILLING CONDITIONS ON ALLOY HOMOGENEITY}

In previous work, portions of individual powder particles which are devoid of aluminium and strengthening dispersoid have been linked to attrition of the alloy steel milling media. Fragments of the milling media removed during milling become entrained within the MA alloy and may effect alloy properties even in the consolidated state. ${ }^{[2]}$

It has been observed that the occurrence of these depleted regions within ODS- $\mathrm{Fe}_{3} \mathrm{Al}$ powder particles is affected by the milling conditions used for a particular batch of powder. Powder milling under vacuum results in lower amounts of depleted material and this has been tentatively linked to the welding of MA alloy to the milling media, thus protecting them from attrition.

As MA under vacuum has other significant effects on the MA powder such as increased particle size, it would not be practical to prescribe vacuum MA as a method to reduce mill attrition in all alloy systems. However, the link between vacuum MA and the inclusion of mill fragments into MA powder is worth bearing in mind during the design of MA powder production routes.

\subsection{THE EFFECT OF PRECONSOLIDATION SIEVING OF ODS-Fe ${ }_{3} A 1$ POWDER}

In a previous report it was suggested that removal of the largest size fraction of as-MA ODS$\mathrm{Fe}_{3} \mathrm{Al}$ by sieving could improve alloy quality due to the high percentage of large powder particles containing large aluminium-depleted regions. ${ }^{[2]}$ These regions are thought to be fragments of milling ball and therefore contain no strengthening dispersoid. Furthermore, dispersoid-free regions in consolidated $\mathrm{ODS}-\mathrm{Fe}_{3} \mathrm{Al}$ have been associated with the retention of fine-grained material within secondary recrystallised microstructures. ${ }^{[3]}$ Sieving of ODS-Fe $\mathrm{F}_{3} \mathrm{Al}$ alloy batches PMWY1, 2 and 3 with $425 \mu \mathrm{m}$ ( 40 mesh) sieves and subsequent consolidation of PMWY2 has been performed by ORNL and the associated material has been analysed during the current study.

Longitudinal and transverse sections of consolidated, sieved PMWY2 bar were subject to a metallographic comparison with similar sections of material that had been manufactured to identical specifications but had not been sieved prior to consolidation. Both the unsieved and sieved powders were consolidated by extrusion at $\approx 1000^{\circ} \mathrm{C}$ with an extrusion ratio of $16: 1$.

Examination of the PMWY2 bar produced from the sieved powder showed that it was generally much 'cleaner' than the alloy produced from unsieved powder, the latter containing high concentrations of particle stringers, presumably $\mathrm{Al}_{\mathrm{x}}(\mathrm{O}, \mathrm{N})_{\mathrm{y}}$, together with numbers of finegrained stringers amongst the coarse secondary recrystallised grain structures. The percentage fractions of fine-grained stringers present were found to be $0.06 \%$ in the sieved material and $0.31 \%$ in the unsieved material. Figures 17 and 18 show polarization contrast images of selected 
regions of the microstructures in the consolidated, sieved and unsieved alloy bars, respectively. Figure 17 reveals faint secondary recrystallised grain boundaries and an alloy generally low in oxide stringer and fine grain content, while Fig. 18 shows fine-grained regions and $\mathrm{Al}_{\mathrm{x}}(\mathrm{O}, \mathrm{N})_{\mathrm{y}}$ particle stringers (yellow).

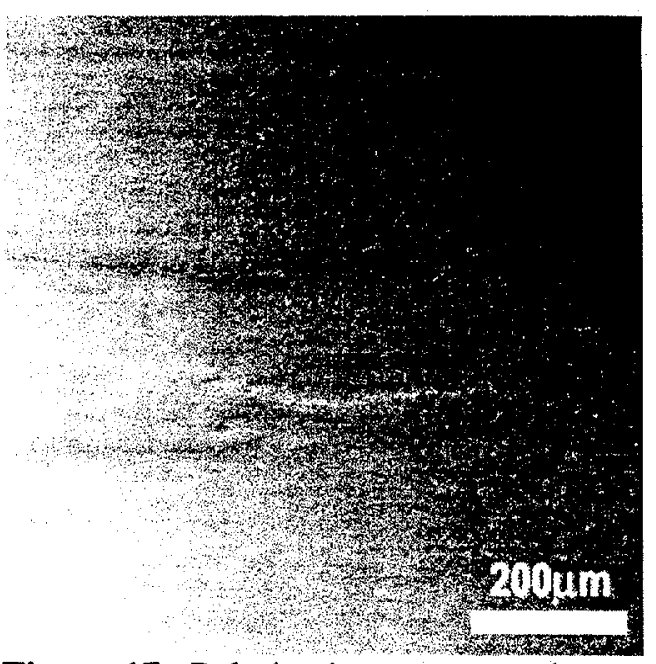

Figure 17 Polarization contrast micrograph of consolidated alloy PMWY2 from which the coarsest powder fraction has been removed before consolidation.

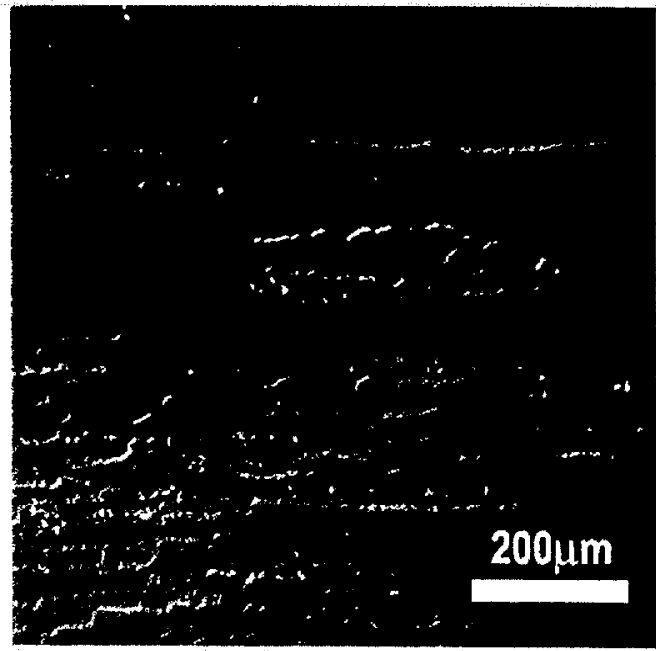

Figure 18 Polarization contrast micrograph of consolidated alloy PMWY2 that underwent no pre-consolidation sieving.

Overall, it appears that the sieving process has led to an improvement in the quality of the consolidated alloy bar of the type predicted i.e. a reduction in the incidence of retained finegrained regions in the secondary recrystallised microstructure. However, it is unclear why sieving to remove particles larger than $425 \mu \mathrm{m}$ ( $40 \mathrm{mesh}$ ) prior to consolidation should reduce the amount of entrained $\mathrm{Al}_{\mathrm{x}}(\mathrm{O}, \mathrm{N})_{\mathrm{y}}$. This suggests that while the consolidation procedures for the bars produced from the sieved and un-sieved powders were notionally identical, factors that may have affected residual oxide levels probably varied subtly. In fact, the results presented earlier suggest that $\mathrm{ODS}-\mathrm{Fe}_{3} \mathrm{Al}$ powder has a propensity for oxidation during pre-consolidation annealing. Hence subtle differences in the degassing and annealing schedules between the consolidated sieved and un-sieved powders may account for the differences in $\mathrm{Al}_{x}(\mathrm{O}, \mathrm{N})_{\mathrm{y}}$ observed in the products. It should be noted that the alloy produced from un-sieved powder had an unusually high defect concentration that could affect its validity as a benchmark alloy.

\section{STIMULATION OF INTERCHANGE OF NON-CONFIDENTIAL INFORMATION, EXPERIENCE AND MATERIALS}

This activity has continued at a low level during the course of the current term of the project. Plansee $\mathrm{GmbH}$ has continued to support the progress of the current work by making free issue PM2000 powders available for benchmarking and other purposes. However, the potential links which should have led to the inclusion of ODS Fe $\mathrm{Fl}_{3}$ coupons in the Sydkraft biomass combustion plant at Värnamo in Sweden did not emerge. The high temperature gasifier remains in operation and further opportunities for in-plant exposure will certainly be available during the fall, when the plant moves out of its low load summer operation into higher temperature more continuous operational cycles. Opportunity for this form of plant exposure might be worth reexamination.

Within COST 522 the University of Liverpool has a zero funded project within the novel components work package of the Plant Integration \& Ancilliary Components Group. Currently 
this work package also includes partners such as Ansaldo Richerche, Alstom Power, Special Metals and Plansee. Individual projects within the work package are aimed at developing an ODS combustor and, separately, a high temperature heat exchanger of bayonet tube design. ODS alloys also feature in the latter project. Standard issues of concern in such projects continue to be availability of materials with appropriate properties and practicable joining techniques.

\section{CONCLUSIONS}

- The advance of the secondary recrystallisation front is hindered by high concentrations of alumina particles. These particles pin grain boundaries, restricting grain growth. The mechanism responsible is Zener pinning, which is exacerbated by the planar arrays of alumina present in ODS $\mathrm{Fe}_{3} \mathrm{Al}$.

- Areas that are denuded in the strengthening YAG dispersoid exist in the alloy. Such areas easily recover and may trigger local recrystallisation that is restricted in extent and interferes with the general process of secondary recrystallisation to coarse grain structures.

- The high concentration of particulate $\mathrm{Al}_{x}(\mathrm{O}, \mathrm{N})_{\mathbf{y}}$ found entrained within consolidated ODS$\mathrm{Fe}_{3} \mathrm{Al}$ originates from oxide scale formed on the alloy powder during high temperature, preconsolidation annealing. This phenomenon may, to some extent, be common to all powder metallurgy $\mathrm{FeCrAl}$ alloys. However, the oxidation characteristics of $\mathrm{ODS}-\mathrm{Fe}_{3} \mathrm{Al}$ render it especially susceptible.

- The inhibition of pre-consolidation powder oxidation should not only reduce the amount of entrained oxide in the consolidated alloy but also reduce the frequency of stringers of retained fine-grained material found within the coarse-grained secondary recrystallised microstructure.

- Two methods by which powder oxidation may be inhibited have been explored. The methods are not mutually exclusive and may be used synergistically, if appropriate, in a variety of alloy systems.

- Hydrogen purging of the canned powder lowers the oxygen partial pressure and establishes a mildly reducing atmosphere around the powder. It reduces oxidation on both ODS-Fe $\mathrm{F}_{3} \mathrm{Al}$ and PM2000 powders but has the most significant effect (green sinter strength) on the latter alloy.

- Cold compaction prior to heat treatment reduces the free surface area of the powder, promotes sintering and reduces the amount of powder oxidation occurring during annealing, greatly improving sintering efficiency.

- Separation of metal powder fractions in terms of density alone has been achieved using a novel fluidised bed technique. The technique is very efficient when density differences are high $(\approx 60 \%)$ but is limited at this stage to density differences above $\approx 12 \%$ where separation is much less efficient. The potential of this technique for refinement is considered to be excellent.

- The incidence of aluminium-depleted inhomogeneities in powder particles varied between batches. The lowest incidence of such inhomogeneities was found in MA powder processed under vacuum.

- Removal of the largest powder particle size fraction ( $>425 \mu \mathrm{m}$ [40 mesh]) from a powder charge prior to consolidation led to an increase in consolidated alloy quality; specifically a lower incidence of retained fine-grained regions. It is considered that this improvement may be due to the removal of larger fragments of dispersoid-free material originating from attrition of the steel ball charge and ordinarily included during consolidation.

- Refinements to the manufacturing process to reduce levels of alumina and limit the formation of dispersoid-free zones would promote efficient, coarse-grained secondary recrystallisation. This would enable reduced annealing times to be used and achieve more complete secondary recrystallisation. 


\section{ACKNOWLEDGEMENTS}

This research was sponsored by the Advanced Research Materials (ARM) Programme, U.S. Department of Energy, Office of Fossil Energy under contract DE-AC05-96OR22464 managed by U.T.-Battelle, LLC.

The fluidised bed separation work was performed by C. Dechsiri and Prof. A.C. Hoffmann at the Chemical Engineering Department, University of Groningen, Nijenborgh 4, 9747 AG Groningen, Netherlands

\section{REFERENCES}

[1] Jones, A.R. and Ritherdon, J.: Proc. $13^{\text {th }}$ Annual Conf. on Fossil Energy Materials, Knoxville, Tennessee, May 11-13, 1999, Eds. Judkins et al. (ORNL 1999), paper 2.4

[2] Ritherdon, J. and Jones, A.R.: Proc. 14 ${ }^{\text {th }}$ Annual Conf. on Fossil Energy Materials, Knoxville, Tennessee, April 25-27, 2000, Eds. Judkins et al. (ORNL 2000), paper 2.3

[3] Ritherdon, J., Jones, A.R. and Wright, I.G.: Proc. $21^{\text {st }}$ Ris $\emptyset$ Symposium on Materials Science, Roskilde, Denmark, September 4-8, 2000, publ. Ris $\varnothing$, p.533

[4] Wright, I.G., Pint, B.A., Tortorelli, P.F. and McKamey, C.G. : Proc. $10^{\text {th }}$ Annual Conf. on Fossil Energy Materials, Knoxville, Tennessee, CONF-9605167, ORNL/FMP-96/1 (1996) p.359

[5] Ritherdon, J., Jones, A.R. and Wright, I.G.: Journal of Metastable and Nanocrystalline Materials 10 (2001) 217 also in Materials Science Forum 360-362 (2001) 217

[6] Guoxian, L., Erde, W. and Shoushi, F. : Journal of Alloys and Compounds 223 (1995) p.111

[7] Hartholt, G.P., R. la Rivière, Hoffmann, A.C. and Janssen, L.P.B.M "Separating Solids from a Mixture in a Gas-Solid Fluidised Bed" International patent application PCT/NL95/00243 submitted by Verenigde Octrooibureaux, Groningen, Den Haag July, 1995

[8] Hartholt, G.P., la Rivière, R., Hoffmann, A.C. and Janssen, L.P.B.M : Powder Technol. 93 (1997), pp.185-188

[9] Dechsiri, C., Bosma, J.C., Dehling, H.G., Hoffmann, A.C. and Hui, G."A Stochastic Model for Particle Mixing and Segregation in Fluidized Beds with baffles" Proceedings of PARTEC 2001 International Congress for Particle Technology, Nuremberg, Germany March 2001

[10] Hoffmann, A.C., "Manipulating fluidized beds by using internals: Fluidization with baffles", NPT Procestechnologie 7(2) (2000), pp.20-24 
ALLISON GAS TURBINE DIVISION

P.O. Box 420

Indianapolis, IN 46206-0420

P. Khandelwal (Speed Code W-5)

R. A. Wenglarz (Speed Code W-16)

\section{BABCOCK \& WILCOX}

Domestic Fossil Operations

20 South Van Buren Avenue

Barberton, OH 44023

M. Gold

\section{CRANFIELD UNIVERSITY}

Power Generation Technology Centre

Cranfield, Bedfordshire

MK43 OAL, United Kingdom

J. Oakey

CANADA CENTER FOR MINERAL \& ENERGY

TECHNOLOGY

568 Booth Street

Ottawa, Ontario

Canada K1A OG1

R. Winston Revie

Mahi Sahoo

COLORADO SCHOOL OF MINES

Department of Metallurgical Engineering Golden, CO 80401

G. R. Edwards

DOE

DOE OAK RIDGE OPERATIONS

P. O. Box 2008

Building 4500N, MS 6269

Oak Ridge, TN 37831

M. H. Rawlins
DOE

National Energy Technology Laboratory

3610 Collins Ferry Road

P.O. Box 880

Morgantown, WV 26507-0880

D. C. Cicero

F. W. Crouse, Jr.

R. A. Dennis

N. T. Holcombe

W. J. Huber

T. J. McMahon

J. E. Notestein

DOE

National Energy Technology Laboratory 626 Cochrans Mill Road

P.O. Box 10940

Pittsburgh, PA 15236-0940

A. L. Baldwin

G. V. McGurl

U. Rao

L. A. Ruth

T. M. Torkos

DOE

OFFICE OF FOSSIL ENERGY

FE-72

19901 Germantown Road

Germantown, MD 20874-1290

F. M. Glaser

DOE

OFFICE OF BASIC ENERGY SCIENCES

Materials Sciences Division

ER-131 GTN

Washington, DC 20545

H. M. Kerch 
FOSTER WHEELER DEVELOPMENT CORPORATION

Materials Technology Department

John Blizard Research Center

12 Peach Tree Hill Road

Livingston, NJ 07039

J. L. Blough

IDAHO NATIONAL ENGINEERING

LABORATORY

P.O. Box 1625

Idaho Falls, ID 83415

R. N. Wright

LEHIGH UNIVERSITY

Materials Science \& Engineering

Whitaker Laboratory

5 E. Packer Avenue

Bethlehem, PA 18015

J. N. DuPont

OAK RIDGE NATIONAL

LABORATORY

P.O. Box 2008

Oak Ridge, TN 37831

M. P. Brady

P. T. Carlson

J. M. Crigger ( 2 copies)

R. R. Judkins

C. T. Liu

M. L. Santella

J. H. Schneibel

R. W. Swindeman

P. F. Tortorelli

I. G. Wright
PACIFIC NORTHWEST LABORATORY

P. O. Box 999, K3-59

Battelle Boulevard

Richland, WA 99352

R. N. Johnson

THE UNIVERSITY OF LIVERPOOL

Liverpool, United Kingdom

L69 3BX

A. R. Jones

THE WELDING INSTITUTE

Abington Hall, Abington

Cambridge CB1 6AL

United Kingdom

P. L. Threadgill

UNIVERSITY OF CALIFORNIA

AT SAN DIEGO

Department of Applied Mechanics and

Engineering Sciences

La Jolla, CA 92093-0411

B. K. Kad

UNIVERSITY OF TENNESSEE AT

\section{KNOXVILLE}

Materials Science and Engineering

Department

Knoxville, TN 37996

P. K. Liaw

WEST VIRGINIA UNIVERSITY

Department of Physics

Morgantown, WV 26506-6315

B. R. Cooper 